\title{
COMPLICAÇÕES AGUDAS DAS DOENÇAS HEPÁTICAS CRÔNICAS
}

\author{
ACUTE COMPLICATIONS OF CHRONIC LIVER DISEASES
}

Ana L.C. Martinelli' ${ }^{1}$ Marcos V. Carneiro²; Manoel A.L. Lescano²; Fernanda F. Souza² \& Andreza C. Teixeira ${ }^{2}$

${ }^{1}$ Docente. ${ }^{2}$ Pós-graduandos. Divisão de Gastroenterologia. Departamento de Clínica Médica. Faculdade de Medicina de Ribeirão Preto -USP. Correspondência: Prof. Dr. Ana LC Martinelli. Divisão de Gastroenterologia. Departamento de Clínica Médica. Faculdade de Medicina de Ribeirão Preto - USP. Avenida Bandeirantes, 3900 - Campus da USP - CEP 14048-900 - Ribeirão Preto, SP, Brasil.

Fax: 55166336695 - e-mail:adlcmart@fmrp.usp.br

MARTINELLI ALC; CARNEIRO MV; LESCANO MAL; SOUZA FF \& TEIXEIRA AC. Complicações agudas das doenças hepáticas crônicas. Medicina, Ribeirão Preto, 36: 294-306, abr./dez. 2003.

RESUMO - As doenças hepáticas crônicas, em fases avançadas, cursam com graves complicações, responsáveis pela maioria das indicações de internações hospitalares e causas de morte dos pacientes. Neste capítulo, são discutidas as principais complicações das doenças hepáticas crônicas, que são a encefalopatia hepática, a peritonite bacteriana espontânea e a síndrome hepatorrenal. São apresentados os aspectos importantes, na prática médica, dessas três condições clínicas, com ênfase na abordagem diagnóstica e terapêutica.

UNITERMOS - Encefalopatia Hepática. Síndrome Hepatorrenal. Peritonite Bacteriana Espontânea. Cirrose.

\section{I - ENCEFALOPATIA HEPÁTICA}

\section{1- INTRODUÇÃO}

A encefalopatia hepática $(\mathrm{EH})$ é definida como uma síndrome neuropsiquiátrica, potencialmente reversível, caracterizada por mudanças na personalidade e no comprometimento da cognição, da função motora e do nível de consciência. Pode ocorrer em pacientes com cirrose hepática, shunts portossistêmicos (espontâneos ou cirúrgicos) ou insuficiência hepática fulminante ${ }^{(1,2)}$. O diagnóstico diferencial deve ser feito com condições nas quais sinais e sintomas neuropsiquiátricos ocorrem, embora secundários a outras etiologias, que também podem ocorrer em pacientes com hepatopatias, e incluem hipoglicemia, distúrbios metabólicos e hidroeletrolíticos ${ }^{(2)}$. Manifestações neurológicas, comumente encontradas em doenças hepáticas específicas, que cursam com envolvi- mento do sistema nervoso central, como doença de Wilson (acúmulo de cobre) e doença hepática alcoólica (incluindo síndrome de abstinência), também devem ser incluídas no diagnóstico diferencial de EH.

\section{2- PATOGÊNESE}

Diferentes hipóteses têm sido apresentadas para explicar as mudanças no estado mental, que ocorrem nos pacientes com $\mathrm{EH}^{(2)}$. Contudo, é difícil explicar toda a variabilidade do quadro clínico com apenas uma teoria e, por isso, acredita-se que a patogênese da encefalopatia hepática seja multifatorial e envolva fatores interdependentes ${ }^{(3)}$.

De modo geral, as teorias se baseiam em três condições básicas: acúmulo plasmático de neurotoxinas, efeito de falsos neurotransmissores e ação de substâncias neuroinibitórias. A seguir, cada teoria será descrita resumidamente. 
- NEUROTOXINAS - A amônia (NH3) é produzida no intestino por proteólise de alimentos, hidrólise da uréia sanguínea, ao atravessar a mucosa intestinal, e, nas hemorragias digestivas, pela degradação do sangue por bactérias da luz intestinal. A amônia é transportada até o fígado, sendo metabolizada no ciclo da uréia. Em pacientes com insuficiência hepática ou shunts portossistêmicos, a formação da uréia está prejudicada, havendo elevação plasmática de $\mathrm{NH}_{3}$. A amônia atravessa a barreira hemoliquórica (BHL), sendo metabolizada nos astrócitos, causando uma série de eventos neuroquímicos, que culminam com alteração da função da célula e, conseqüentemente, da neurotransmissão normal. Ressalta-se, entretanto, que os níveis séricos de amônia não estão diretamente relacionados com a gravidade da $\mathrm{EH}^{(4)}$.

- FALSOS NEUROTRANSMISSORES - Em pacientes com cirrose, há diminuição dos níveis de aminoácidos de cadeia ramificada (ACR): valina, leucina e isoleucina; e aumento dos aminoácidos de cadeia aromática (ACA): triptofano, fenilanina e metionina. Os ACAs atravessam facilmente a BHL e competem com neurotransmissores normais, como a dopamina e a norepinefrina. Estudos clínicos, com administração oral ou parenteral de ACR em pacientes com EH, não têm mostrado melhora significativa dos sintomas ${ }^{(4)}$.
- ACÚMULO DE SUBSTÂNCIAS NEUROINIBITÓRIAS - O ácido $\gamma$-aminobutírico (GABA) é o principal representante desta classe e é sintetizado, no sistema nervoso central e no intestino grosso, a partir do glutamato. Nos pacientes com cirrose hepática, a hiperamoniemia, que pode ser associada ou agravada por situações em que há sangue retido nos cólons, facilita a produção do GABA, que atravessa a BHL e pode inibir a neurotransmissão. Os diazepínicos endógenos também são neuroinibidores, mas seu papel, na EH, é controverso ${ }^{(3)}$.

- HIPERMANGANESEMIA - Estudos demonstram que mais de $80 \%$ dos pacientes com cirrose, em coma hepático, têm níveis séricos de manganês aumentados. A exposição prolongada a esse metal resulta em sintomas extrapiramidais e anormalidades na ressonância nuclear magnética do $\mathrm{SNC}^{(3,4,5)}$.

- DEFICIÊNCIA DE ZINCO - A diminuição plasmática de zinco, em pacientes com cirrose hepática, tem sido associada com EH, mas, ainda, há controvérsias a esse respeito ${ }^{(3)}$.

\section{3- FATORES DESENCADEANTES}

Os principais fatores desencadeantes de EH estão mostrados na Tabela I, juntamente com os respectivos mecanismos de ação.

Tabela I - Principais fatores desencadeantes de encefalopatia hepática e possíveis mecanismos de ação

Fatores desencadeantes Mecanismos de ação

Hemorragia digestiva Cerca de $100 \mathrm{ml}$ de sangue na luz intestinal produz 15-20g de proteínas, que, degradadas pelas bactérias intestinais, geram substâncias nitrogenadas (amônia).

Constipação intestinal Coproestase propicia geração de amônia pelas bactérias intestinais.

Sedativos Ação depressora direta no SNC (ativação da neurotransmissão inibitória).

Excesso de ingestão protéica Oferta excessiva de substâncias nitrogenadas.

Distúrbio hidroeletrolítico

Uso indevido de diuréticos ou DEEC leva à hipopotassemia ou hiponatremia, que podem contribuir para EH. Alcalose metabólica facilita a difusão da amônia pela BHL.

Infecções Catabolismo protéico aumentado leva à formação de amônia.

Paracentese Paracentese volumosa (mais de 5 1), sem reposição de expansor plasmático, pode desencadear EH, por mecanismo não esclarecido.

SNC: sistema nervoso central; DEEC: depleção do espaço extracelular; EH: encefalopatia hepática; BHL: barreira hematoliquórica. 


\section{4- QUADRO CLÍNICO E DIAGNÓSTICO}

O episódio agudo de EH, no paciente cirrótico, é caracterizado pelo desenvolvimento de uma síndrome confusional aguda, com prejuízo do estado mental, alterações neuromusculares, fetor hepaticus e distúrbios respiratórios. O início é, habitualmente, abrupto, e, muitas vezes, está associado a fatores desencadeantes, e sua evolução depende do curso da doença hepática ou da remoção desses fatores ${ }^{(2,3)}$.

As manifestações neuropsiquiátricas da EH não são específicas e podem estar presentes em outras condições clínicas. As alterações psíquicas podem variar de confusão leve ao coma, e, normalmente, apresentam como primeira manifestação clínica, a alteração súbita da personalidade ou a inversão do ritmo do sono; distúrbios de comportamento, desorientação, confusão, bradilalia, estupor e coma podem estar presentes em quadros mais avançados ${ }^{(2,3,4)}$.

$\mathrm{Na}$ avaliação dos distúrbios neuromusculares, há predomínio de hipertonia e hiper-reflexia com sinal do extensor plantar na fase pré-comatosa, e hipotonia e hipo ou arreflexia, no coma profundo ${ }^{(3)}$. O tremor grosseiro de extremidades (asterixis ou flapping) é o sinal mais característico da fase pré-comatosa, e representa a inabilidade de manutenção ativa da postura ou posição. $\mathrm{O}$ asterixis corresponde a movimentos das mãos, do tipo batimento de asas, quando os braços são mantidos em extensão horizontal, ou quando o antebraço é mantido fixo e as mãos posicionadas em um ângulo de 60 graus em relação ao punho (hiperextensão do punho). Não está presente no coma profundo ${ }^{(2,3,6)}$.

Outros componentes da encefalopatia hepática são o fetor hepaticus, atribuído a um composto sulfurado volátil, que é percebido, no hálito do paciente, como um odor desagradável, e a hiperventilação, um mecanismo compensatório que visa reduzir o $\mathrm{pH}$ arterial, diminuindo a entrada de amônia no cérebro ${ }^{(2)}$.

O diagnóstico da EH é baseado na história clínica, no exame físico e em alguns exames laboratoriais, que reforçam o diagnóstico de $\mathrm{EH}$ e outros que permitem a exclusão de doenças com manifestações neurológicas semelhantes às da EH. Exames de imagem, como a tomografia computadorizada do cérebro, são recomendados, para exclusão de anormalidades estruturais, nos pacientes com encefalopatia grave ou na ausência de fatores desencadeantes. O eletroencefalograma apresenta resultados inespecíficos, e a análise do líquor deve ser reservada para os casos em que há suspeita de meningoencefalite infecciosa.
Em virtude da freqüente presença de fatores desencadeantes na EH, como peritonite bacteriana espontânea e hemorragia digestiva, recomenda-se a punção de líquido ascítico, em todo paciente com ascite, e realização de toque retal naqueles pacientes com suspeita de sangramento digestivo não referido.

A classificação da $\mathrm{EH}$ em graus, de acordo com a gravidade, ${ }^{(3)}$ apresenta grande importância no seguimento dos pacientes, permitindo a avaliação das alterações de consciência, da função intelectual e do comportamento, conforme mostra a Tabela II.

Tabela II - Graus de gravidade da encefalopatia hepática, avaliados clinicamente.

\section{Grau Manifestações neuropsiquiátricas}

1 Alterações psicométricas; mudanças no ciclo do sono, no humor e no comportamento. Presença ou não de asterixis.

2 Sonolência e desorientação. Presença de asterixis.

3 Estupor ou coma com resposta a estímulos.

4 Coma profundo sem resposta a estímulos.

\section{5- TRATAMENTO}

\section{1- Medidas Gerais}

- Identificação e remoção dos fatores desencadeantes

- Suspensão de diuréticos

- Sondas nasogástrica e urinária podem ser necessárias

- Sonda orotraqueal e suporte ventilatório no coma profundo

\section{2- Nutrição}

- Nos pacientes com encefalopatia, graus 3 e 4, o suporte calórico, nas primeiras 24-48 h deve ser realizado com infusão endovenosa de solução de glicose. Nos casos em que, após esse período, não for possível a introdução de dieta por via oral, pode ser utilizada a via enteral ${ }^{(5,7)}$.

- A dieta deve conter $0,5 \mathrm{~g}$ proteína $/ \mathrm{kg} /$ dia nos primeiros dias, com aumento progressivo de 10 a $20 \mathrm{~g}$ a cada 2 ou 3 dias, até atingir 1-1,5g/kg/dia. Recomenda-se dar preferência à proteína de origem vegetal ou utilizar leite e derivados ${ }^{(2,5)}$. 
- Nos casos de necessidade de maior aporte protéico, o uso de aminoácidos de cadeia ramificada pode ser considerado ${ }^{(2)}$.

\section{3- Medicamentos}

- Dissacarídeos não absorvíveis - Lactulose ( $\beta$-galactosidofructose): terapia padrão. Após sua administração, a lactulose é metabolizada por bactérias da flora bacteriana cecal, causando redução do pH no intestino e indução do aumento da excreção fecal de nitrogênio, e conseqüentemente, queda na quantidade de amônia plasmática. A dose inicial recomendada é de 10-30 ml, via oral ou por sonda nasogástrica, 3-4 vezes por dia até início das evacuações, ou como enema (300-500ml de lactulose em 1 litro de água filtrada); após, ajustar a dose com o objetivo de manter 2 a 3 evacuações pastosas/dia. Lactitol ( $\beta$-galactosidosorbitol): melhor paladar e menos efeitos adversos (distensão abdominal, flatulência e diarréia). Não disponível no Brasil ${ }^{(6)}$.

- Neomicina - Alternativa aos dissacarídeos não absorvíveis. Aminoglicosídeo com pouca absorção pelo tubo gastrintestinal $(<4 \%)$, contudo com risco de toxicidade renal e auditiva, quando utilizado por longos períodos. A dose inicial recomendada é de 3 a $6 \mathrm{~g} / \mathrm{dia}$, via oral, por 2 a 3 dias; em seguida, de 1 a $2 \mathrm{~g} /$ dia nos dias posteriores, evitando-se uso prolongado $^{(6,7)}$.

- Flumazenil - Antagonista seletivo de receptores centrais dos benzodiazepínicos. Produz melhora transitória das alterações mentais, contudo pode estar indicado para melhorar o nível de consciência de pacientes em coma profundo, evitando-se entubação orotraqueal. A dose preconizada é de 0,4 a 2,0 mg, via endovenosa, em bolus. Recomenda-se que seu uso seja reservado para os casos em que haja suspeita de que a EH foi desencadeada por benzodiazepínicos ${ }^{(2,6,7)}$.

- Suplementação com zinco - O zinco é um cofator do ciclo da uréia, frequientemente deficiente nos pacientes cirróticos, em decorrência de excreção urinária ou desnutrição. A dose proposta de acetato de zinco é de $220 \mathrm{mg}$, duas vezes ao dia, por via oral. Os resultados clínicos da suplementação de zinco são controversos, sendo recomendada avaliação prévia de deficiência ${ }^{(5)}$.

\section{REFERÊNCIAS BIBLIOGRÁFICAS}

1 - SCHIAVON LL \& KIKUCHI LOO. Complicações no paciente cirrótico. In: HIGA MS \& ATALLAH AN, eds. Medicina de urgência - Guias de Medicina Ambulatorial e HospitaIar UNIFESP, Manole, São Paulo, p.351-353, 2004.

2 - CORDOBA J \& BLEI AT. Hepatic encephalopathy. In: SCHIFF ER; SORRELL MF \& MADDREY WC, eds. Diseases of the liver, $9^{\text {th }}$ ed, Lippincott Williams \& Wilkins, Philadelphia, p.595623, 2003.

3 - ROSA H. Encefalopatia hepática. In: CASTRO LP \& COELHO LGV, eds. Gastroenterologia, Medsi, Rio de Janeiro, p.267277, 2004.

4 - ABOU-ASSI S \& VLAHCEVIC RZ. Hepatic encephalopathy. Postgrad Med 109: 52-54, 2001.

5 - CORDOBA J \& BLEI AT. Hepatic encephalopathy. Am J Gastroenterol 96:1968-1976, 2001.

6 - SHERLOCK S \& DOOLEY J. Hepatic encephalopathy. In: SHERLOCK $S$ \& DOOLEY J, eds. Disease of the liver and biliary system, $11^{\text {th }}$ ed, Blackwell Publishing, Oxford, p.93110, 2002.

7 - RORDAN SM \& WILLIAMS R. Treatment of hepatic encephalopathy. N Engl J Med 337: 473-479, 1997.

\section{II - PERITONITE BACTERIANA ESPONTÂ- NEA}

\section{1- INTRODUÇÃO}

Peritonite bacteriana espontânea (PBE) representa a principal complicação infecciosa do paciente cirrótico $^{(1)}$. Apesar de raramente, ter sido descrita em outras situações, tais como, síndrome nefrótica ou insuficiência cardíaca congestiva, a maior parte dos episódios ocorre em pacientes com doença hepática grave.

A prevalência da $\mathrm{PBE}$, em pacientes cirróticos, admitidos em hospital, é estimada em $10-30 \%{ }^{(1,2)}$, tais valores aumentam, quando associada a outras condições, como hemorragia digestiva.

Nas últimas décadas, observou-se queda significativa da mortalidade, associada a PBE, a qual era cerca de $90 \%$, e, na atualidade, em torno de $20 \%$. O aumento na sobrevida devem-se à abordagem diagnóstica mais agressiva (análise sistemática do líquido ascítico), a disponibilidade de antibióticos mais eficazes e seguros e a medidas de prevenção da recorrência da infeção.

Atualmente, a paracentese é considerada procedimento seguro, mesmo em cirróticos com distúrbios de coagulação, deixando de existir o temor com respeito às suas complicações ${ }^{(3)}$. Preconiza-se reali- 
zar paracentese diagnóstica em todo paciente cirrótico com ascite, nas circunstâncias indicadas a seguir ${ }^{(4)}$.

- Ao ingressar em hospital.

- No momento do diagnóstico da ascite.

- Quando houver sinais ou sintomas de peritonite (dor abdominal, dor à descompressão brusca, vômito, diarréia).

- Na presença de sinais de infecção sistêmica (febre, leucocitose, choque séptico).

- Em casos de encefalopatia hepática ou de alteração da função renal.

- Em situações de hemorragia digestiva.

\section{2- DEFINIÇÃO E VARIANTES DA INFEÇÃO DO LÍQUIDO ASCÍTICO (LA) (TABELA I)}

PBE - Infecção do LA, definida pela contagem de polimorfonucleares (PMN) $\geq 250 / \mathrm{mm}^{3}$ de LA e cultura positiva do LA, na ausência de foco infeccioso abdominal, cirurgicamente tratável.

Ascite Neutrocítica Cultura Negativa - Essa variante é diagnosticada, quando o resultado da cultura do LA é negativo e a contagem de $\mathrm{PMN} \geq 250 / \mathrm{mm}^{3}$ de LA. Em termos práticos, essa entidade apresenta o mesmo prognóstico da PBE, devendo ser tratada de maneira similar.

Bacteriascite Monomicrobiana Não Neutrocítica - Essa variante é caracterizada pelo isolamento da bactéria na cultura do LA e PMN $<250 / \mathrm{mm}^{3}$ no LA. O curso clínico difere das duas entidades anteriores e depende da presença ou ausência de sintomas clínicos.

Peritonite Bacteriana Secundária - Entidade caracterizada pela associação de cultura positiva do LA e contagem de PMN $\geq 250 / \mathrm{mm}^{3}$ de LA, na presença de fonte de infecção cirurgicamente tratável. Quinze porcento dos episódios de peritonite bacteriana, em pacientes cirróticos, são secundários, sendo o quadro clínico indistinguível da PBE. A presença de outros critérios sugere o diagnóstico de infecção secundária.

- Falha de resposta ao tratamento antibiótico.

- Cultura polimicrobiana (principalmente anaeróbios ou fungos).

- No mínimo, dois dos seguintes parâmetros bioquímicos no LA:

Glicose $>50 \mathrm{mg} / \mathrm{dl}$.

Proteína $>1 \mathrm{~g} / \mathrm{dl}$.

DHL > $225 \mathrm{U} / \mathrm{ml}$ (ou maior que o limite superior da normalidade do soro).

\section{3- ETIOLOGIA}

Aproximadamente 60 a $70 \%$ dos episódios de PBE são causados por bactérias gram negativas, entre as quais predominam Escherichia coli e Klebsiella pneumoniae $^{(5)}$.

Gram-positivos são responsáveis por cerca de $25 \%$ dos casos de PBE, os quais, geralmente, pertencem à família dos estreptococos. Após a introdução do uso de quinolonas, na profilaxia secundária da PBE, tem sido relatado pequeno aumento da incidência de episódios de infecção do LA, causados por gram-positivos.

\section{4- FISIOPATOLOGIA}

Sugere-se, atualmente, que a maioria dos episódios de PBE seja resultado da translocação bacteriana de origem intestinal. Inicialmente, o microorganismo migra para os linfonodos mesentéricos, passando pelo ducto torácico para ingressar, posteriormente, na corrente sanguínea. Finalmente, a bactéria coloniza o LA, ficando na dependência dos fatores bactericidas (principalmente capacidade de opsonização), existentes no líquido, a evolução para infecção.

Tabela I - Condições associadas à infecção do líquido ascítico (LA)

\begin{tabular}{|l|l|l|}
\hline Nomenclatura & $\mathbf{N}^{\boldsymbol{o}} \mathbf{P M N} / \mathbf{m m}^{\mathbf{3}}$ & Cultura do $\mathbf{L A}$ \\
\hline PBE & $\geq 250$ & positiva (geralmente, 1 organismo) \\
\hline Ascite neutrocítica cultura negativa & $\geq 250$ & negativa \\
\hline Bacteriascite monomicrobiana não neutrocítica & $<250$ & positiva (1 organismo) \\
\hline Peritonite bacteriana secundária & $\geq 250$ & positiva (polimicrobiana)
\end{tabular}




\section{5- FATORES PREDISPONENTES}

A gravidade da doença hepática é, provavelmente, o principal fator para o desenvolvimento da infecção do LA. Aproximadamente, $70 \%$ dos episódios acontecem em pacientes cirróticos da classe Child $C$.

Baixas concentrações de proteína do LA se relacionam diretamente com capacidade bactericida diminuída do fluido ascítico, sendo utilizado o valor de proteína no $\mathrm{LA}<1 \mathrm{~g} / \mathrm{dl}$, como fator de risco para desenvolvimento da $\mathrm{PBE}^{(6)}$.

Vinte a trinta por cento dos episódios de hemorragia aguda gastrointestinal cursam com PBE no momento da admissão hospitalar, fato explicado pelo aumento da translocação bacteriana e da permeabilidade intestinal, como conseqüência do sangramento ${ }^{(7)}$.

Bacteriúria é comum em pacientes cirróticos, principalmente em mulheres, podendo ser uma fonte para desenvolvimento da PBE. Sondagem vesical, na medida do possível, deve ser evitada nesse tipo de paciente.

Cateteres intravasculares são freqüentemente usados, principalmente na unidade de cuidados intensivos, promovendo bacteremia e posterior possível infeção do LA. O uso dos cateteres deve ser minimizado em tal população.

Pacientes que sobrevivem a um episódio de PBE têm um risco de $70 \%$ de desenvolver um novo episódio infeccioso no período de um ano.

\section{6- QUADRO CLÍNICO}

Os sintomas, geralmente apresentam-se de maneira insidiosa, sendo observados com mais freqüência, febre (69\%) e dor abdominal (59\%). Outros sinais e sintomas incluem encefalopatia hepática, diarréia, íleo e alteração da função renal. Aproximadamente $10 \%$ dos pacientes não apresentam qualquer sintoma. Devido a pouca especificidade dos sintomas, qualquer deterioração clínica do paciente deve ser indicativa de realização de paracentese diagnóstica.

\section{7- DIAGNÓSTICO}

A suspeita diagnostica é feita com base no quadro clínico.

A paracentese diagnóstica inclui a colheita de LA para citologia e cultura e, quando necessários, outros testes de análise no LA.
A paracentese é um procedimento seguro, mesmo na presença de coagulopatia ou plaquetopenia, freqüentes, não existindo, na maioria dos casos, contraindicação absoluta para sua realização, e não havendo necessidade de transfusões de sangue ou derivados para correção dos distúrbios hematológicos ${ }^{(3)}$.

A citologia do LA possibilita a contagem do número de PMN, fundamental para o diagnóstico de PBE. Valor de PMN $\geq 250 / \mathrm{mm}^{3}$ de LA é considerado indicativo de infecção do LA, sendo o resultado da cultura irrelevante para se indicar o início do tratamento ${ }^{(4)}$.

Ocasionalmente, o LA pode vir hemorrágico (>10.000 hemacias $/ \mathrm{mm}^{3}$ ), seja por acidente de punção ou condições que causem hemorragia dentro do LA, como neoplasia. Nestes casos, propõe-se um fator de correção, subtraindo 1 PMN para cada 250 glóbulos vermelhos encontrados.

O LA deve ser inoculado em frascos de hemocultura, tanto para aeróbio como anaeróbio, à beira do leito. São necessários $10 \mathrm{ml}$ de LA, no mínimo, em cada frasco. Mesmo otimizando as técnicas, resultados de cultura são negativos em aproximadamente 40 a $50 \%$ dos casos ${ }^{(5,8)}$.

Os casos de bacteriascite $\left(\mathrm{PMN}<250 / \mathrm{mm}^{3}\right.$ de LA e cultura do LA positiva) comportam-se de maneira diferente dos quadros de ascite neutrocítica e de PBE, evoluindo, na maioria das vezes, com resolução espontânea. Sugere-se, em tais casos, repetir a paracentese, com realização de outra citologia e cultura do LA após 48 h da primeira. Na Figura 1, mostramos o algoritmo de manejo dos casos de bacteriascite.

\section{8- TRATAMENTO}

A escolha dos esquemas antibióticos mudou nos últimos anos. Deve ser ressaltado que pacientes com PBE são muito sensíveis a drogas nefrotóxicas, tendo sido abandonado o uso de aminoglicosídeos.

Na década de 80, iniciou-se o uso de cefalosporinas de terceira geração, com ótimos resultados, sendo que permanece como o primeiro esquema antibiótico até atualmente. Na Europa e nos Estados Unidos, a droga de eleição é a cefotaxima, no entanto, o uso de outra cefalosporina de terceira geração, a ceftriaxona, mostrou resultados similares ${ }^{(9)}$. O tempo mínimo de tratamento preconizado é de cinco dias.

Outros esquemas antibióticos têm sido utilizados, como alternativa às cefalosporinas, com resultados promissores (Tabela II). 


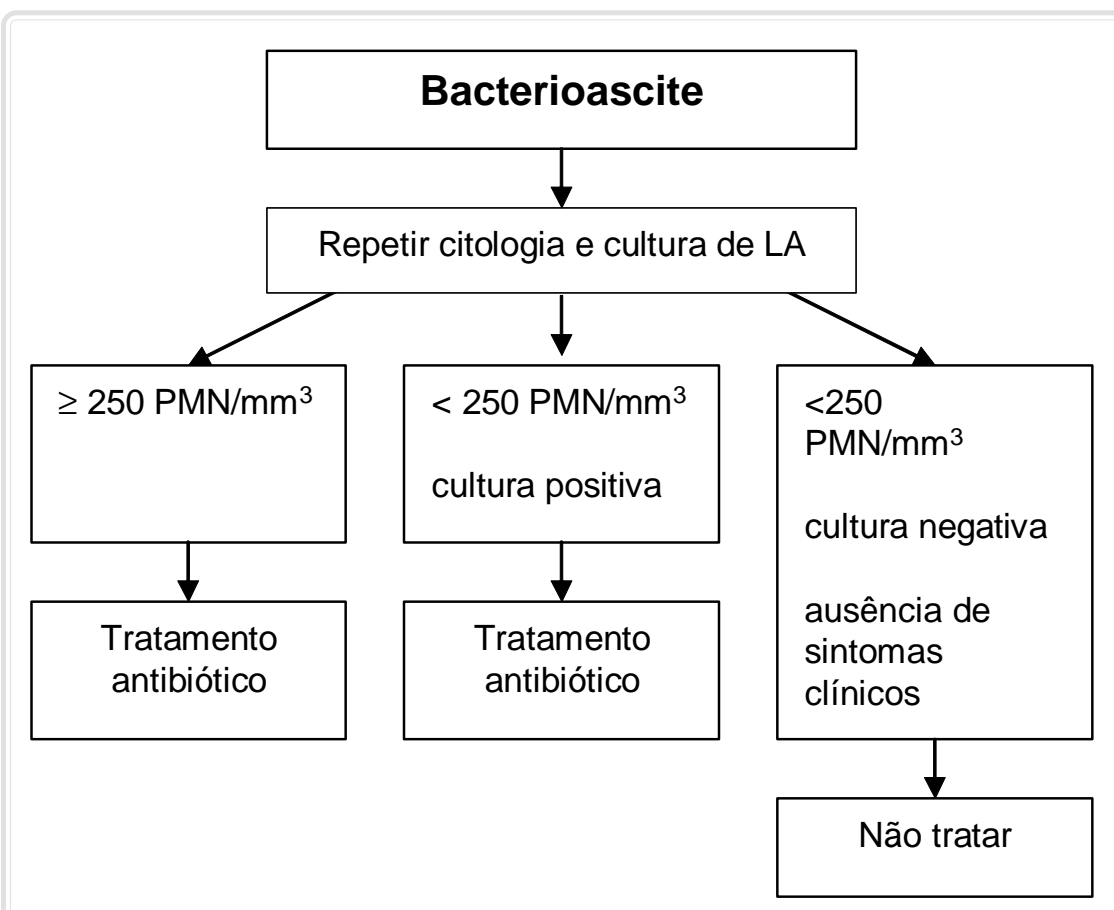

Figura 1 - Algoritmo de manejo dos casos de bacteriascite.

\section{9- CONTROLE DE TRATA- MENTO}

A melhora clínica é observada, na maioria dos pacientes, após o início do uso do antibiótico. Mesmo assim, é recomendação do International Ascitis Club (IAC) ${ }^{(4)}$ que se faça o controle de parâmetros do LA $48 \mathrm{~h}$ após o início do esquema antibiótico. Os critérios de resposta ao tratamento são: queda de $>25 \%$ do número de PMN em relação à contagem basal (antes do início do antibiótico), assim como melhora dos sinais e sintomas de infecção. Caso não se observarem tais critérios de resposta ao tratamento, pode-se optar pela mudança do esquema antibiótico, segundo o antibiograma obtido da cultura do LA, entretanto, devese considerar a possibilidade de peritonite bacteriana secundária.
O uso de ofloxacina oral, ambulatorialmente, em pacientes com PBE não complicada (ausência de choque séptico, encefalopatia, sangramento intestinal, insuficiência renal ou íleo), mostrou índices de resolução da infecção similares àqueles observados com cefotaxima ( 84 vs. $85 \%$ ), abrindo a possibilidade de tratamento sem necessidade de internação hospitalar, em grupo selecionado ${ }^{(10)}$. Esta conduta é pouco utilizada em nosso meio, pois a maioria dos pacientes apresenta complicações na admissão.

\section{0- COMPLICAÇÕES DA PBE}

\section{Insuficiência Renal}

Representa o principal preditor de mortalidade, e acontece em, aproximadamente, $30 \%$ dos pacientes infectados. Essa disfunção ocorre como resultado de maior redução no volume plasmático arterial efetivo, mediado pelo incremento de citocinas circulantes, induzido pela infecção.

Tabela II - Principais esquemas de tratamento para Peritonite Bacteriana Espontânea

\begin{tabular}{|c|c|c|c|}
\hline Antibiótico & Via de administração & Dose & Duração \\
\hline Ceftriaxona $^{(4,9)}$ & IV & $2 \mathrm{~g} / \mathrm{dia}$ & 5 dias \\
\hline Cefotaxima $^{(4)}$ & IV & $2 \mathrm{~g} 2 \mathrm{x} / \mathrm{dia}$ & 5 dias \\
\hline Amoxacilina-ácido clavulânico ${ }^{(4)}$ & IV/VO & $\begin{array}{l}1,2 \mathrm{~g} \mathrm{IV} 3 \mathrm{x} / \mathrm{dia} / 2 \text { dias e, depois, } \\
625 \mathrm{mg} \text { VO } 3 \mathrm{x} / \mathrm{dia} \text {, por } 6-12 \text { dias }\end{array}$ & 8-14 dias \\
\hline Ofloxacina ${ }^{(4,10)}$ & VO & $400 \mathrm{mg} \mathrm{2x/dia}$ & 8 dias \\
\hline Ciprofloxacina ${ }^{(11)}$ & IV/VO & $\begin{array}{l}200 \mathrm{mg} \text { IV } 2 \mathrm{x} / \mathrm{dia} / 2 \mathrm{dias} \text { e, depois } \\
500 \mathrm{mg} \text { VO } 2 \mathrm{x} / \mathrm{dia} \text {, por } 5 \mathrm{dias}\end{array}$ & 7 dias \\
\hline
\end{tabular}


Recente publicação ${ }^{(12)}$ mostrou uma expectativa favorável na diminuição dessa complicação, utilizando expansores plasmáticos. Os autores estudaram 126 pacientes com PBE, subdivididos em dois grupos. Um grupo usou antibiótico isolado, e o outro grupo antibiótico e albumina $\mathrm{EV}(1,5 \mathrm{~g} / \mathrm{kg} / \mathrm{dia}$ no primeiro dia e $1,0 \mathrm{~g} / \mathrm{kg} / \mathrm{dia}$ no terceiro dia). O grupo de tratamento combinado mostrou redução significativa da alteração da função renal (10\% vs. 33\%) e da mortalidade hospitalar (10\% vs. $28 \%$ ), quando comparado ao grupo de tratamento convencional. O maior inconveniente de tal medida profilática é o custo da albumina.

Medidas para prevenir complicações renais, como evitar o uso de antiinflamatórios, restringir a administração de diuréticos no período de infecção e evitar paracenteses evacuadoras (não drenar > 4 litros), devem ser adotadas.

\section{Hemorragia Digestiva Alta}

Similar à piora da função renal, o mecanismo mais provável da ruptura das varizes esofágicas é a alteração do sistema hemodinâmico em um paciente com uma disfunção circulatória prévia. Não existe nenhuma medida preventiva para tal condição.

\section{Encefalopatia Hepática}

Pacientes com PBE podem desenvolver encefalopatia, devendo-se evitar a complicação com medidas que afastem outros fatores desencadeantes da encefalopatia como constipação intestinal, uso de diuréticos e alterações hidroeletrolíticas.

\section{1- PROFILAXIA}

Muitos grupos de pacientes cirróticos em alto risco de desenvolver PBE, têm sido identificados, podendo ser divididos em dois grupos (Tabela III): pacientes cirróticos com e sem hemorragia gastrintestinal.

\section{Pacientes cirróticos com Hemorragia Gastrintestinal}

Todos os pacientes cirróticos com sangramen- to intestinal, independente da presença ou ausência de ascite, encontram-se em alto risco de desenvolver infeções bacterianas, incluindo PBE. Aproximadamente 20 a 30\% das infecções são diagnosticadas no momento da admissão hospitalar.

Foi comprovado que o uso de antibióticos, profilaticamente, nessa população, diminui a incidência de episódios de PBE. Atualmente, o antibiótico recomendado pela IAC é a norfloxacina $400 \mathrm{mg}$, duas vezes ao dia, por via oral ou por sonda nasogástrica, durante 7 dias. Outras alternativas de antibióticos têm sido descritas, como ciprofloxacina via oral, amoxacilina-clavulonato endovenoso, sendo a via de administração e a disponibilidade do antibiótico escolhidas a critério das condições do paciente.

\section{Pacientes cirróticos sem Hemorragia Gastrintestinal}

Pacientes com episódio prévio de PBE - Resultados de ensaios randomizados demonstram que a administração oral de norfloxacina $400 \mathrm{mg} /$ dia reduz, significativamente, a taxa de recorrência da infecção de $68 \%$ para $20 \%$.

Pacientes com valor baixo de proteína no LA: diferentes estudos mostram que valores de proteína no LA $<1 \mathrm{~g} / \mathrm{dl}$ aumentam a chance de desenvolvimento de PBE (15-20\% em 1 ano); até o momento não existe um consenso, na literatura, a respeito do uso de profilaxia primária em tal condição.

\section{2- PROGNÓSTICO}

O prognóstico dessa condição é bastante pobre. A sobrevida no $1^{\circ}$ e no $2^{\circ}$ ano, após o primeiro episódio de PBE, é estimada em 30-50\% e $25-30 \%$, respectivamente ${ }^{(13)}$; com relatos, na literatura, mais sombrios de até $30 \%$ em 6 meses ${ }^{(14)}$.

O transplante hepático confere uma sobrevida muito maior; devendo ser, portanto, considerada a possibilidade de realização do procedimento após o primeiro episódio de PBE.

\section{Tabela III - Medidas para prevenção da infecção do LA.}

Pacientes com sangramento intestinal: - norfloxacina $400 \mathrm{mg}$, duas vezes ao dia, via oral ou sonda nasogástrica, por 7 dias

Pacientes com episódio prévio de

peritonite bacteriana espontânea: - norfloxacina $400 \mathrm{mg} /$ dia, indefinidamente. 


\section{REFERÊNCIAS BIBLIOGRÁFICAS}

1 - CALY WR \& STRAUSS E. A prospective study of bacterial infections in patients with cirrhosis. J Hepatol 18: 353-358, 1993.

2 - SUCH J \& RUNYON BA. Spontaneous bacterial peritonitis. Clin Infect Dis 27: 669-674, 1998.

3 - RUNYON BA. Paracentesis of ascitic fluid: A safe procedure. Arch Intern Med 146: 2259-2261, 1986.

4 - RIMOLA A; GARCÍA-TSAO G; NAVASA M; PIDDOCK LJ; PLANAS R; BERNARD B \& INADOMI JM. Diagnosis, treatment and prophylaxis of spontaneous bacterial peritonitis: a consensus document. J Hepatol 32: 142-153, 2000.

5 - RUNYON BA; CANAWATTI HN \& AKRIVIADIS EA. Optimization of ascitic fluid culture technique. Gastroenterology 95: 1351-1355, 1988.

6 - RUNYON BA. Patient with deficient ascitic fluid opsonic activity are predisposed to spontaneous bacterial peritonitis. Hepatology 8: 632-635, 1988.

7 - BERNARD B; CADRANEL J-F; VALLA D; ESCOLANO S; JARLIER V \& OPOLON P. Prognostic significance of bacterial infection in bleeding cirrhotic patients: A prospective study. Gastroenterology 108: 1828-1834, 1995.

8 - BOBADILLA M; SIFUENTES J \& GARCIA-TSAO G. Improved method for bacteriological diagnosis of spontaneous bacterial peritonitis. J Clin Microbiol 27: 2145-2147, 1989.

9 - FRANÇAAVC; GIORDANO HM; SEVA-PEREIRAT \& SOARES EC. Five days of ceftriaxone to treat spontaneous bacterial peritonitis in cirrhotic patients. J Gastroenterol 37: 119122, 2002.

10 - NAVASA M; FOLLO A; LLOVET JM; CLEMENTE G; VARGAS V; RIMOLAA; MARCO F; GUARNER C; FORNE M; PLANAS R; BANARES R; CASTELLS L; JIMENEZ DE ANTA MT; ARROYO V \& RODES J. Randomized, comparative study of oral ofloxacin versus intravenous cefotaxime in spontaneous bacterial peritonitis. Gastroenterology 111: 1011-1017, 1996.

11 - TERG R; COBAS S; FASSIO E; LANDEIRA G; RIOS B; VASEN W; ABECASIS R; RIOS H; GUEVARA N. Oral ciprofloxacin after a short course of intravenous ciprofloxacin in the treatment of spontaneous bacterial peritonitis: results of a multicenter, randomized study. J Hepatol 33: 564-569, 2000.

12 - SORT P; NAVASA M; ARROYO V; ALDEGUER X; PLANAS R; RUIZ-DEL-ARBOL L; CASTELLS L; VARGAS V; SORIANO G; GUEVARA M; GINES P \& RODES J. Effect of intravenous albumin on renal impairment and mortality in patients with cirrhosis and spontaneous bacterial peritonitis. $\mathbf{N}$ Engl J Med 341: 403-409, 1999.

13 - MOWAT C \& STANLEY AJ. Spontaneous bacterial peritonitis-diagnosis, treatment and prevention. Aliment Pharmacol Ther 15: 1851-1859, 2001.

14 - FRANÇA AVC; DE SOUZA JB J; SILVA CM \& SOARES EC. Long-Term prognosis of cirrhosis after spontaneous bacterial peritonitis treated with ceftriaxone. J Clin Gastroenterol 33:295-298, 2001.

\section{III- SÍNDROME HEPATORENAL}

\section{1- DEFINIÇÃO}

Síndrome hepatorrenal (SHR) é definida como uma condição que ocorre em pacientes com doença hepática crônica e insuficiência hepática avançada e hipertensão portal, caracterizada por função renal alterada, e graves anormalidades na circulação arterial renal e na atividade de sistemas vasoativos endógenos ${ }^{(1)}$.

A probabilidade de desenvolvimento de SHR, em pacientes cirróticos com ascite, é de cerca de $20 \%$ em um ano e de $40 \%$ em 5 anos ${ }^{(2)}$.

\section{2- FISIOPATOLOGIA}

A SHR é caracterizada por insuficiência renal devido à intensa vasoconstricção da circulação renal. O mecanismo de vasoconstricção não é completamente compreendido. Acredita-se que a insuficiência renal seja causada por alterações hemodinâmicas, conseqüentes à vasodilatação arterial. Assim, propõe-se que SHR seja o resultado da ação de sistemas vasoconstrictores (sistema reninoangiotensina, sistema nervoso simpático, sistema vasopressinarginina) sobre a circulação renal, como resposta homeostática a extrema vasodilatação da circulação arterial esplâncnica. Como resultado da atividade aumentada desses sistemas vasoconstrictores, a perfusão renal e a taxa de filtração glomerular diminuem substancialmente, mas a função tubular mantém-se preservada ${ }^{(1,3 / 6)}$. Em fases precoces, com cirrose compensada, a perfusão renal é mantida pela síntese aumentada de vasodilatadores renais, principalmente prostaglandinas. Em fases tardias, a perfusão renal não pode ser mantida, devido à vasodilatação extrema da circulação esplâncnica, que causa ativação máxima dos sistemas vasoconstrictores, produção diminuída de vasodilatadores renais, ou ambos, e a SHR se desenvolve. Na Figura 1, estão esquematizados os mecanismos fisiopatológicos, envolvidos na SHR.

A SHR é classificada em dois diferentes tipos (tipo 1 e 2), os quais, provavelmente, representam expressões distintas do mesmo mecanismo patogênico ${ }^{(1)}$

A SHR do tipo 1 é caracterizada por aumento rápido e progressivo dos níveis de uréia e creatinina séricas em um curto período de tempo (os valores de creatinina sérica inicial dobram para níveis acima de $2,5 \mathrm{mg} / \mathrm{dl}$ ou a clearance de creatinina de $24 \mathrm{~h}$ inicial 


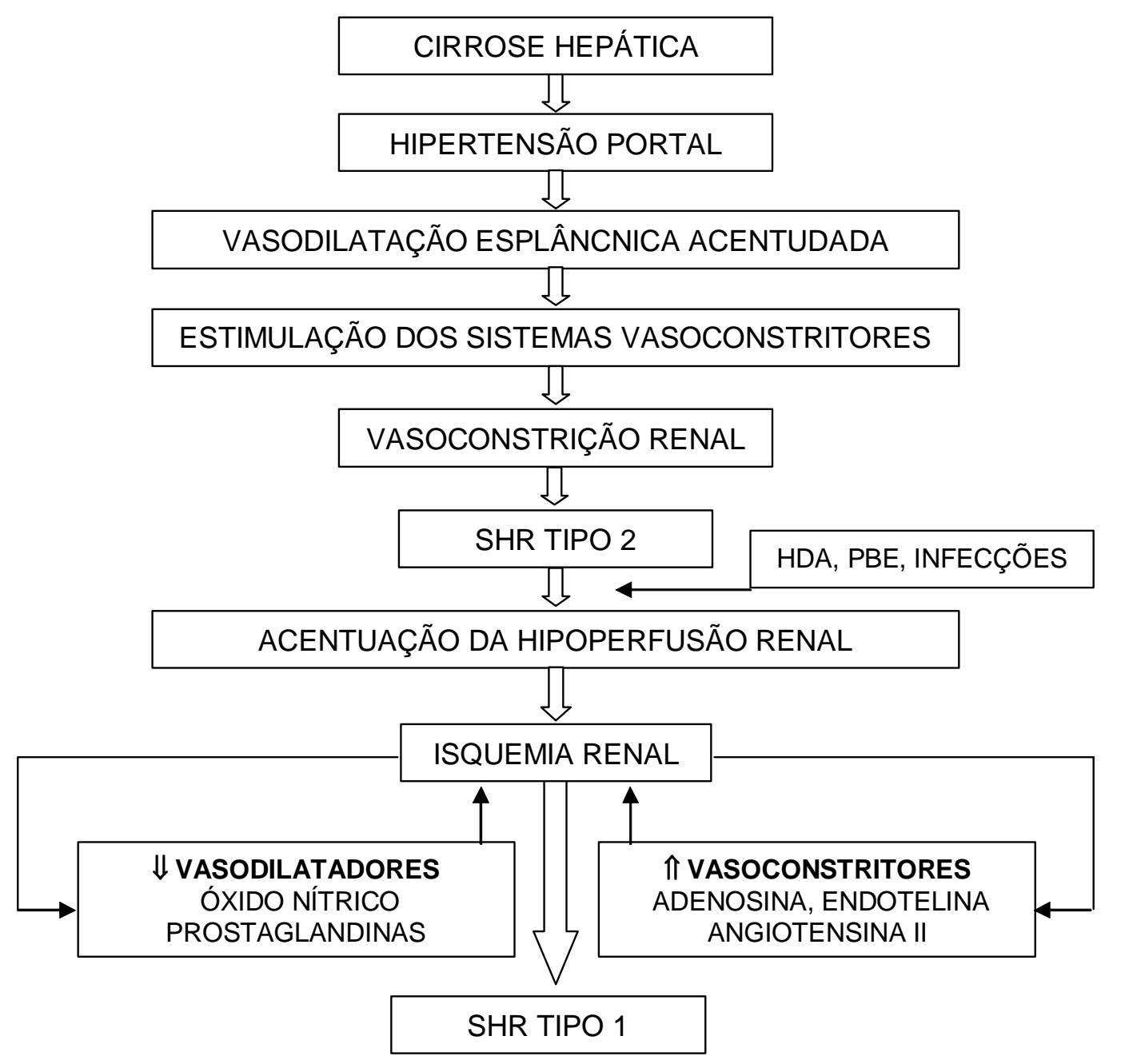

Figura 1 - Mecanismos fisiopatológicos, envolvidos na SHR. Adaptado da referência 3. HDA: hemorragia digestiva alta; PBE: peritonite bacteriana espontânea.

reduz em 50\% para valores menores que $20 \mathrm{ml} / \mathrm{min}$, em um período de 2 semanas). Embora possa ocorrer em pacientes com função renal prévia preservada, a SHR do tipo 1, comumente, desenvolve-se em pacientes que já apresentam SHR do tipo 2, expostos a algum fator precipitante, como infecções bacterianas (particularmente peritonite bacteriana espontânea), hemorragia digestiva, cirurgias, paracentese sem utilização de expansores plasmáticos, hepatite aguda (álcool, vírus, tóxicos) superimposta a cirrose, entre outras. Quase todos os pacientes, se não tratados, morrem após 2-3 semanas depois do início da deterioração da função renal ${ }^{(3)}$.

A SHR do tipo 2 é caracterizada por redução moderada da função renal (creatinina sérica entre 1,5 a 2,5 mg/dl, não atingindo os valores que são critérios para SHR do tipo 1), a qual permanece estável durante meses, sem tendência a progredir com o passar do tempo. Ocorre, geralmente, em pacientes com função hepática relativamente preservada, sendo que a maioria apresenta ascite refratária ${ }^{(3)}$.

\section{3- DIAGNÓSTICO}

O diagnóstico de SHR deve ser feito após a exclusão de outras causas de insuficiência renal, em pacientes cirróticos, particularmente a insuficiência renal pré-renal e a necrose tubular aguda.

Os critérios diagnósticos ${ }^{(1)}$ para SHR são encontrados na Tabela I. 
Tabela I - Critérios diagnósticos da SHR

Principais

- Taxa de filtração glomerular reduzida: Creatinina sérica $>1,5 \mathrm{mg} / \mathrm{dl}$ ou clearance de creatinina de $24 \mathrm{~h}<40 \mathrm{ml} / \mathrm{min}$.

- Ausência de choque, infecções bacterianas, uso atual ou recente de agentes nefrotóxicos, perdas líquidas pelo trato gastrintestinal (vômitos repetidos ou diarréia intensa) ou rins (perda de peso corporal $>500 \mathrm{~g} /$ dia na ausência de edema periférico ou $>1000 \mathrm{~g} / \mathrm{dia}$, se houver edema periférico).

- Ausência de melhora sustentada na função renal (creatinina $<1,5 \mathrm{mg} / \mathrm{dL}$ ou aumento do clearance de creatinina de

$24 \mathrm{~h}>40 \mathrm{ml} / \mathrm{min}$ após retirada de diuréticos e expansão do volume plasmático (infusão endovenosa de $1500 \mathrm{ml}$ de solução salina).

Adicionais

- Volume urinário $<500 \mathrm{~mL} / \mathrm{dia}$.

- Sódio urinário $<10 \mathrm{mEq} / \mathrm{L}$.

- Osmolalidade urinária maior que a osmolalidade plasmática.

- Número de hemácias na urina $<50$ por campo.

- Sódio sérico $<130 \mathrm{mEq} / \mathrm{L}$

Adaptado da referência 1.

\section{4- PROGNÓSTICO}

A sobrevida dos pacientes com SHR é ruim e a recuperação espontânea muito rara ${ }^{(2)}$. Na SHR do tipo 1 a sobrevida é de cerca de $10 \%$, e o tempo de sobrevida médio é de 2 semanas, se não houver tratamento. Na SHR do tipo 2, o tempo de sobrevida é de $50 \%$ em 6 meses.

\section{5- TRATAMENTO}

Embora o transplante hepático seja o único método efetivo e definitivo de tratamento da SHR, o tratamento clínico da síndrome pode possibilitar que o paciente sobreviva até o momento do transplante, além do que a melhora da função renal diminui a morbidade e a mortalidade pós-transplante. Desse modo, as terapias empregadas visam melhorar a função renal definitivamente ou temporariamente até a realização do transplante hepático.

Os pacientes com SHR do tipo 2 devem usar diuréticos para o tratamento de ascite, somente se estes estiverem causando uma natriurese significativa (> $30 \mathrm{mEq} / \mathrm{dia})$. Pacientes com ascite de grande volume ou tensa devem ser tratados com paracenteses associadas à infusão endovenosa de albumina (6-8g por litro de líquido ascítico retirado). Adicionalmente, recomenda-se restrição de sal na dieta $(40-80 \mathrm{mEq}$ de sódio por dia). Restrição da ingestão de líquidos $(1000 \mathrm{~mL} / \mathrm{dia})$ pode ser feita em casos de hiponatremia (sódio sérico < $130 \mathrm{mEq} / \mathrm{L}$ ).
A administração de dopamina e prostaglandinas é ineficaz no tratamento de pacientes com SHR do tipo $1^{(7,8)}$.

A única terapia clínica atualmente disponível é a utilização de agentes vasoconstrictores, que são efetivos em cerca de $30 \%$ dos pacientes com SHR do tipo $1^{(9 / 14)}$. Acredita-se que os agentes melhorem a função circulatória, por causar vasoconstricção do leito arterial esplâncnico, extremamente dilatado, com supressão da atividade dos sistemas vasoconstrictores endógenos, o que resulta na melhora da perfusão renal ${ }^{(15)}$. Dois tipos de drogas têm sido utilizados: análogos da vasopressina (terlipressina) ou agonistas alfaadrenérgicos (norepinefrina, midodrina), em combinação com albumina (Tabela II).

O TIPS (transjugular intrahepatic portosystemic shunting) parece ser, também, efetivo no tratamento de pacientes com SHR, entretanto os dados ainda são limitados. O principal efeito do TIPS é diminuir a pressão portal. Na SHR do tipo 1, o TIPS melhora a função circulatória e reduz a atividade dos sistemas vasoconstrictores, resultando em aumento da perfusão renal e da taxa de filtração glomerular, e queda nos níveis de creatinina sérica em cerca de $60 \%$ dos pacientes ${ }^{(16,17)}$.

A hemodiálise não deve ser rotineiramente usada em pacientes com SHR do tipo 1, uma vez que não interfere na evolução natural do quadro. Contudo, pode ser utilizada como ferramenta temporária até a realização do transplante hepático, em pacientes que não responderam à terapia medicamentosa ${ }^{(18)}$. 
Tabela II - Esquemas de tratamento da SHR
Droga
Dose
Referência

Vasoconstrictores

Terlipressina $\dagger$

0,5 a 2,0 $\mathrm{mg} 4 / 4 \mathrm{~h} \mathrm{EV} \mathrm{em} \mathrm{bolus}$

$9 / 12$

Norepinefrina $\dagger$

0,5 a $3,0 \mathrm{mg} / \mathrm{h}$ EV contínuo

13

$7,5 \mathrm{mg}-12,5 \mathrm{mg}$ VO $3 \mathrm{x} / \mathrm{dia}+$

14

Midodrina* +

100-200 mcg SC 3x/dia

Octreotídio**

Albumina

$1 \mathrm{~g} / \mathrm{Kg} \mathrm{EV}$ no $1^{\circ}$ dia e $20-40 \mathrm{~g} /$ dia após

$9,10,13,14$

Duração

5 a 15 dias

Objetivo

Reduzir creatinina sérica para valores $<1,5 \mathrm{mg} / \mathrm{dl}$

Adaptado das referências 3 e 17. Administrar um dos vasoconstrictores associado à albumina.

† Possíveis efeitos colaterais com terlipressina e norepinefrina: isquemia cardíaca, esplâncnica e periférica.

* midodrina: dose inicial de 7,5mg 3x/dia, podendo ser aumentada até $12,5 \mathrm{mg} \mathrm{3x} /$ dia.

** octreotídio: dose inicial de $100 \mathrm{mcg} 3 \mathrm{x} / \mathrm{dia}$, podendo ser aumentada até $200 \mathrm{mcg} 3 \mathrm{x} / \mathrm{dia}$.

\section{6- PREVENÇÃO}

Medidas devem ser tomadas para se evitarem os fatores precipitantes da SHR.

A SHR ocorre em cerca de $30 \%$ dos pacientes com peritonite bacteriana espontânea. Nessa condição, a administração endovenosa de albumina $(1,5 \mathrm{~g} / \mathrm{Kg}$ no diagnóstico da infecção e de $1,0 \mathrm{~g} / \mathrm{Kg} 48$ h após), em associação com o uso de antibiótico, reduz o risco do desenvolvimento de SHR, quando comparado com o tratamento convencional com uso apenas do antibiótico (10\% x $33 \%$, respectivamente), assim como a mortalidade $(10 \% \times 29 \% \text {, respectivamente })^{(19)}$.

Em pacientes com hepatite aguda alcoólica, observou-se a diminuição da taxa de ocorrência de SHR, com a administração de pentoxifilina (400 mg $3 \mathrm{x}$ ao dia, via oral), o que se observa, quando se faz a comparação com o grupo-controle $(8,2 \%$ x $34,6 \%$, respectivamente), assim como a taxa de mortalidade $(24,5 \% \times 46,1 \% \text {, respectivamente })^{(20)}$.

\section{REFERÊNCIAS BIBLIOGRÁFICAS}

1 - ARROYO V; GINÈS P; GERBES AL; DUDLEY FJ; GENTILINI P; LAFFI G; REYNOLDS TB; RING-LARSEN H \& SCHÖLMERICH J. Definition and diagnostic criteria of refractory ascites and hepatorenal syndrome in cirrhosis. Hepatology 23:164-173, 1996.
2 - GINÈS A; ESCORSELL A; GINÈS P; SALO J; JIMENEZ W; INGLADA L; NAVASA M; CLARIA J; RIMOLA A \& ARROYO V. Incidence, predictive factors, and prognosis of the hepatorenal syndrome in cirrhosis with ascites. Gastroenterology 105:229-236, 1993.

3 - GINÈS P; GUEVARA M; ARROYO V \& RODÉS J. Hepatorenal syndrome. Lancet 362: 1819-1827, 2003.

4 - ARROYO V; GUEVARA M \& GINÈS P. Hepatorenal syndrome in cirrhosis: pathogenesis and treatment. Gastroenterology 122:1658-1676, 2002.

5 - SCHRIER RW; ARROYO V; BERNARDI M; EPSTEIN M; HENRIKSEN JH \& RODES J. Peripheral arterial vasodilation hypothesis: a proposal for the initiation of renal sodium and water retention in cirrhosis. Hepatology 8:1151-1157, 1988.

6 - SCHRIER RW; NIEDERBERGER M; WEIGERT A \& GINÈS P. Peripheral arterial vasodilation: determinant of functional spectrum of cirrhosis. Semin Liver Dis 14:14-22, 1994.

7 - SALÓ J; GINÈS A; QUER JC; FERNANDEZ-ESPARRACH G; GUEVARA M; GINĖS P; BATALLER R; PLANAS R; JIMENEZ W; ARROYO V \& RODÉS J. Renal and neurohormonal changes following simultaneous administration of systemic vasoconstrictors and dopamine or prostacyclin in cirrhotic patients with hepatorenal syndrome. J Hepatol 25:916-923, 1996.

8 - GINÈS A; SALMERÓN JM; GINÈS P; ARROYO V; JIMENEZ W; RIVERA F \& RODES J. Oral misoprostol or intravenous prostaglandin E2 do not improve renal function in patients with cirrhosis and ascites with hyponatremia or renal failure. J Hepatol 17:220-226, 1993. 
9 - URIZ J; GINÈS P; CARDENAS A; SORT P; JIMENEZ W; SALMERON JM; BATALLER R; MAS A; NAVASA M; ARROYO $\checkmark$ \& RODES J. Terlipressin plus albumin: an effective and safety therapy of hepatorenal syndrome. J Hepatol 33:4348, 2000.

10 - MOREAU R; DURAND F; POYNARD T; DUHAMEL C; CERVONI J-P; ICHAÏ P; ABERGEL A, HALIMI C; PAUWELS M; BRONOWICKI J-P; GIOSTRA E; FLEUROT C; GURNOT D; NOUEL O; RENARD P; RIVOAL M, BLANC P; COUMAROS D; DUCLOUX S; LEVY S; PARIENTE A; PERARNAU J-M; ROCHE J, SCRIBE-OUTTAS M; VALLA D; BERNARD B; SAMUEL D; BUTEL J; HADENGUE A; PLATEKA; LEBREC D \& CADRANEL $\mathrm{J}-\mathrm{F}$. Terlipressin in patients with cirrhosis and type I hepatorenal syndrome: retrospective multicenter study. Gastroenterology 122:923-930, 2002.

11 - MULKAY JP; LOUIS H; DONCKIER V; BOURGEOIS N; ADLER M; DEVIERE J \& LE MOINE O. Long-term terlipressin administration improves renal function in cirrhotics patients with type I hepatorenal syndrome: a pilot study. Acta Gastroenterol Belg 64:15-19, 2001.

12 - ORTEGA R; GINÈS P; URIZ J; CÁRDENAS A; CALAHORRA B; DE LAS HERAS D; GUEVARA M; BATALLER R; JIMÉNEZ W; ARROYO V \& RODÉS J. Terlipressin with and without albumin for patients with hepatorenal syndrome: results of a prospective, nonrandomized study. Hepatology 36:941-948, 2002.

13 - DUVOUX C; ZANDITENAS D; HEZODE C; CHAUVAT A; MONIN $\mathrm{J}$-L; ROUDOT-THORAVAL F; MALLAT A \& DHUMEAUX D. Effects of noradrenalin and albumin in patients with type I hepatorenal syndrome: a pilot study. Hepatology 36:374380, 2002.
14 - ANGELIP; VOLPIN R; GERUNDA G; CRAIGHERO R; RONER P; MERENDA R; AMODIO P; STICCAA; CAREGATO L; MAFFEIFACCIOLI A \& GATTA A. Reversal of type I hepatorenal syndrome with the administration of midodrine and octreotide. Hepatology 29:1690-1697, 1999.

15 - GINÈS P \& GUEVARA M. Good news for hepatorenal syndrome. Hepatology 36;504-506, 2002.

16 - GUEVARA M; GINÈS P; BANDI JC; GILABERT R; SORT P; JIMENEZ W; GARCIA-PAGAN JC; BOSCH J; ARROYO V \& RODES J. Transjugular intrahepatic portosystemic shunt in hepatorenal syndrome: effects on renal function and vasoactive systems. Hepatology 28:416-422, 1998.

17 - BRENSING KA; TEXTOR J; PERZ J; SCHIEDERMAIER P; RAAB P; STRUNK H; KLEHRHU; KRAMER HJ; SPENGLERU; SCHILD $H$ \& SAUERBRUCH T. Long-term outcome after transjugular intrahepatic portosystemic stent-shunt in non-transplant patients with hepatorenal syndrome: a phase II study. Gut 47:288-295, 2000.

18 - GINÈS P; CÁRDENAS A; ARROYO V \& RODÉS J. Management of cirrhosis and ascites. N Engl J Med 350:16461654, 2004.

19 - SORT P; NAVASA M; ARROYO V; ALDEGUER X; PLANAS R; RUIZ-DEL-ARBOL L; CASTELLS L; VARGAS V; SORIANO G; GUEVARA M; GINĖS P \& RODÉS J. Effect of intravenous albumin on renal impairment and mortality in patients with cirrhosis and spontaneous bacterial peritonitis. $\mathbf{N}$ Engl $\mathbf{J}$ Med 341:403-409, 1999.

20 - AKRIVIADIS E; BOTLA R; BRIGGS W; HAN S; REYNOLDS T \& SHAKIL O. Pentoxifyline improves short-term survival in severe acute alcoholic hepatitis: a double-blind, placebocontrolled trial. Gastroenterology 119:1637-1648, 2000.

MARTINELLI ALC; CARNEIRO MV; LESCANO MAL; SOUZAFF \& TEIXEIRA AC. Acute complications of chronic liver diseases. Medicina, Ribeirão Preto, 36: 294-306, apr./dec. 2003.

ABSTRACT - Advanced chronic liver diseases lead to severe complications that are responsible for the majority of indications of hospitalization and patients' death. In this article the main complications of chronic liver diseases such as hepatic encephalopathy, spontaneous bacterial peritonitis and hepatorenal syndrome are discussed. The main aspects in practical clinic of these three clinical conditions with emphasis in the diagnostic and therapeutic approach are shown.

UNITERMS - Hepatic Encephalopathy. Hepatorenal Syndrome. Spontaneous Bacterial Peritonitis. Cirrhosis. 